Artigos

\title{
Abortifacientes: efeitos tóxicos e riscos
}

\author{
Abortive agents: toxic effects and risks
}

\author{
Marli Roehsig, Simone Gomes Sant'Anna, Kátia Regina Rosin Delphino Salles, \\ Marcelo Filonzi dos Santos, Mauricio Yonamine
}

Roehsig M, Sant'Anna SG, Salles KRRD, Santos MF, Yonamine M. Abortifacientes: efeitos tóxicos e riscos. Saúde, Ética \& Justiça. 2011;16(1):1-8.

RESUMO: A prática clandestina do aborto pode provocar diversos efeitos prejudiciais à saúde da mulher. Em muitos casos, a situação política, social e religiosa do Brasil favorece a automedicação e a procura por preparações caseiras e populares para induzir o aborto. Atualmente, medicamentos e plantas são alguns dos métodos empregados para interromper a gestação. Observa-se uma diversificação na legislação do aborto entre os países, com tendência à menor restrição na interrupção da gravidez em países desenvolvidos. É fundamental o envolvimento da iniciativa pública em programas de educação e planejamento familiar da população para que esta esteja capacitada a avaliar suas escolhas e os riscos aos quais se expõe. O objetivo do presente trabalho foi realizar uma revisão bibliográfica e análise crítica dos aspectos toxicológicos de fármacos e de plantas utilizados como abortifacientes, considerando também os riscos associados quando não há um acompanhamento médico efetivo.

DESCRITORES: Abortivos/toxicidade; Abortivos/efeitos adversos; Saúde da mulher; Toxicidade.

Departamento de Análises Clínicas e Toxicológicas, Faculdade de Ciências Farmacêuticas, Universidade de São Paulo.

Endereço para correspondência: Marcelo Filonzi dos Santos. Faculdade de Ciências Farmacêuticas, USP. Av. Prof. Lineu Prestes, 580 - Bloco 13B. CEP: 05508-900 - São Paulo, Brasil. e-mail: filonzi @ usp.br 


\section{INTRODUÇÃO}

A prática clandestina de abortos tem sido uma grande preocupação por parte de especialistas devido às prováveis consequências à saúde e à prevalência de mortes das mulheres que utilizam métodos inapropriados para indução do aborto.

Inúmeros são os casos de mulheres que interrompem a gestação quando se deparam com uma gravidez indesejada por não planejarem ter filhos. O atual panorama político, ético e religioso presente no Brasil favorece a automedicação e a procura por preparações caseiras e populares com a finalidade de induzir o aborto. Tais procedimentos resultam em sérios riscos à saúde destas mulheres, levando frequentemente ao óbito materno. Atualmente, entre os métodos arriscados para indução do aborto, incluem-se a utilização de medicamentos orais e injetáveis, preparações vaginais e o uso de drogas ilícitas. Nos países em desenvolvimento, é de conhecimento que mulheres também utilizam princípios ativos extraídos de partes de plantas ${ }^{1}$.

Os sistemas de saúde, na maioria desses países, não planejam sistematicamente e não fornecem atenção médica de urgência eficaz para mulheres que sofrem complicações relacionadas ao aborto. $O$ tratamento muitas vezes é postergado e ineficaz, com graves consequências e riscos à saúde da mulher ${ }^{2}$, além dos altos gastos públicos devido às complicações da tentativa de aborto.

Dados obtidos do Sistema Nacional de Informações Toxicológicas (SINITOX) mostraram que, em 2008, 95 casos de intoxicação por tentativas de aborto foram registrados, sendo que $26,3 \%$ foram pelo consumo de plantas medicinais na forma de chá, $42,1 \%$ pelo uso de medicamentos, $8,4 \%$ pela ingestão de agrotóxicos de uso agrícola/doméstico, $11,6 \%$ pelo uso de raticidas, 5,3\% produtos domissanitários, 3,2\% dos registros devem-se ao consumo de drogas de abuso, 2,1\% à utilização de produtos químicos e industriais e, em 1\% dos casos, a causa é atribuída a outros meios não relatados. Considerando-se o número de óbitos por tentativa de aborto registrados no mesmo ano, observou-se que o uso de medicamentos e de plantas foram as duas principais causas das mortes maternas ${ }^{3}$.

No Brasil, o emprego de chás e infusões de plantas medicinais, além do misoprostol, comercializado com o nome de Cytotec $^{\circledR}$, está entre os recursos abortifacientes mais comumente utilizados ${ }^{4}$.

O objetivo do presente trabalho foi realizar uma revisão bibliográfica e análise crítica dos aspectos toxicológicos de fármacos e de plantas utilizados como abortifacientes, considerando também os riscos associados quando não há um acompanhamento médico eficiente.

\section{MÉTODOS DE PESQUISA}

A revisão da literatura sobre os fármacos e plantas mais empregados com finalidade abortiva foi realizada através da busca de periódicos que têm suas publicações referentes à temática "Toxicologia" e "Abortifacientes", utilizando inicialmente como termo de busca as palavras: abortivos/abortifacientes e em inglês abortive agents nos principais bancos de dados com abrangência nacional internacional. Esta busca foi feita através da internet e também foram consultados os portais National Library of Medicine (MEDLINE/PubMed), Scopus, Web of Knowledge e SciELO. Também foram pesquisados os sítios oficiais da Organização Mundial da Saúde, Food and Drug Administration (FDA), Código Penal Brasileiro, Ministério da Saúde, Serviço Nacional de Informações TóxicoFarmacológicas (SINITOX), Secretaria de Saúde do Estado do Rio de Janeiro, Banco de Dados Bibliográficos da Universidade de São Paulo (USP) Catálogo On-Line Global - DEDALUS (USP, 1997). A princípio, priorizaram-se os artigos mais recentes (últimos dez anos), entretanto, quando avaliada a falta de informação sobre determinado agente neste período, procuraram-se informações pregressas.

\section{Legislação pertinente}

Há países nos quais a lei permite a realização de aborto. Em outros, ele apenas é liberado em casos especiais e há, ainda, países onde não é permitido aborto em qualquer circunstância. No mundo, cerca de $98 \%$ dos países permitem o aborto no caso de risco para a vida da mulher, $63 \%$ para preservar a saúde física da gestante, 62\% para preservação da saúde mental, 43\% em situações de incesto ou violência, 39\% quando há dano fetal, $33 \%$ por razões sociais e econômicas e apenas $27 \%$ quando há solicitação materna. Mesmo em casos nos quais a mulher está amparada legalmente para realizar o aborto, há situações em que não se dispõe de serviços seguros para a realização do procedimento, o que pode dever-se a problemas no sistema de saúde, como utilização de métodos inadequados ou desatualizados para induzir ao aborto, instalações impróprias e falta de recursos ${ }^{5}$. No Brasil, o Congresso examinou 46 projetos de lei sobre o aborto entre 1946 e 1995; 13 dos 
16 projetos de lei apresentados entre 1991 e 1995 tinham por objetivo legalizar o aborto em certos casos $^{6}$. O Código Penal Brasileiro no Art. 124 considera crime provocar aborto em si mesmo ou consentir que outrem Iho provoque e define como pena a detenção, de um a três anos; e no Art. 128 não se pune o aborto praticado por médico quando não há outro meio de salvar a vida da gestante ou no caso de gravidez resultante de estupro 7 .

Em 2003, uma proposta de descriminalização do aborto foi rejeitada na $12^{\circ}$ Conferência Nacional da Saúde. A 13을 Conferência Nacional da Saúde ocorrida em Brasília rejeitou, em 2007, a proposta de legalização do aborto. O tema ficou fora do relatório final da conferência e não seguiu ao governo como sugestão para ser incluído nas políticas públicas de saúde.

No ano seguinte, o projeto de lei 1135/91, que prevê a extinção dos artigos do código penal que criminalizam o aborto praticado com consentimento da gestante, foi rejeitado por unanimidade na Comissão de Seguridade Social e Família da Câmara dos Deputados. O projeto, que tramitava na casa havia 17 anos, seguiu para a Comissão de Cidadania e Justiça, onde também foi rejeitado8.

O Departamento de Ações Programáticas Estratégicas do Ministério da Saúde elaborou, no Plano de Ação 2004/2007, a Política Nacional de Atenção Integral à Saúde da Mulher, com o objetivo de "promover a atenção obstétrica e neonatal qualificada e humanizada, incluindo a assistência ao abortamentoem condições inseguras, paramulheres e adolescentes", mostrando a preocupação dos profissionais da saúde e reconhecendo a gravidade dos riscos associados ao aborto 9 .

\section{Panorama do aborto no mundo}

A indução do aborto é considerada um grande problema de saúde no mundo, com um total estimado de 46 milhões de casos a cada $a^{10}{ }^{10}$. Segundo a Organização Mundial da Saúde (OMS), a mortalidade ligada aos abortos representa, no mínimo, $13 \%$ da mortalidade materna no mundo. Os métodos inadequados, a ausência de informações e uma legislação restritiva vão geralmente ao encontro das elevadas taxas de mortalidade. A OMS também informa que $25 \%$ de todas as gestações mundiais são interrompidas voluntariamente, sendo cerca de 50 milhões a cada ano. Do total, cerca de 20 milhões de abortos desenvolvem-se em condições perigosas. Nos países em desenvolvimento, estimase que, em cada oito mortes maternas, pelo menos uma está relacionada à tentativa de aborto ${ }^{11}$.
As estimativas mundiais do aborto relacionadas com internações hospitalares em mulheres com idades compreendidas entre 15 a 44 anos em países em desenvolvimento mostram altas taxas de hospitalização, que variam de um mínimo de cerca de 3 por 1000 mulheres internadas em Bangladesh até 15 por 1000 no Egito e Uganda. Nigéria, Paquistão e Filipinas têm taxas de 4 a 7 por 1000 internações e dois países da América Latina (Peru e Guatemala) têm taxas de quase 9 por $1000^{12}$. Além disso, a prática de aborto clandestino é um problema de saúde pública devido aos altos custos hospitalares com pacientes que sofrem complicações decorrentes da indução do aborto ${ }^{13}$.

Para conter o avanço demográfico na China, o aborto é legalizado e muitas vezes há incentivos para a realização deste procedimento. Os chineses consideram a interrupção da gravidez como um importante método de planejamento familiar. São utilizadas intervenções cirúrgicas para a cessação da gravidez e, nas últimas três décadas, numerosos estudos clínicos utilizando prostaglandinas combinadas com ervas chinesas, esteróides ou drogas abortivas foram realizados. A principal desvantagem do aborto médico é o intenso e prolongado sangramento vaginal; portanto cientistas deste país continuam a procurar medicamentos tradicionais chineses mais adequados para resolver este problema ${ }^{14}$.

O Alan Guttmacher Institute publicou em 1994 os resultados da pesquisa feita no Brasil e em mais cinco países da América Latina sobre os casos aborto clandestino. Neste levantamento, estimou-se que em 1991 ocorreu um total de 1.443.350 abortamentos induzidos no Brasil, o que corresponde à taxa de $3,65 \%$ ao ano de abortamentos realizados por mulheres de 15 a 49 anos $^{15}$.

Há um levantamento realizado no Brasil, seguindo a mesma metodologia da Alan Guttmacher Institute, que atualiza as estimativas nas grandes regiões do país entre 1992 e 2005. Os resultados mostram que houve redução de $38 \%$ no número de abortos induzidos no Brasil: de 1.455.283 em 1992 para 1.066.993 em 1996, mantendo-se neste patamar até 2005. Em 2005, três em cada quatro destes abortamentos induzidos ocorreram nas regiões Nordeste e Sudeste. A taxa anual de abortamentos induzidos por mulheres de 15 a 49 anos no Brasil reduziu de 3,69\% em 1992 para $2,07 \%$ em 2005, e a maior incidência ocorre na Região Nordeste com taxa de 2,73\% em 2005. O menor índice $(1,28 \%)$ foi registrado na Região Sul ${ }^{4}$. 
Roehsig M, et al. Abortifacientes: efeitos tóxicos e riscos.

\section{Fármacos utilizados como abortifacientes}

Devido ao índice de mulheres que procuram auxílio médico hospitalar em decorrência de abortos incompletos ou de suas complicações, vários centros de pesquisas mobilizam-se para estudar os riscos à saúde materna associados com uso de fármacos para induzir o aborto.

O misoprostol, comercializado como Cytotec ${ }^{\circledR}$, é um fármaco eficaz para o tratamento de úlceras gástricas, principalmente as induzidas pelos antiinflamatórios não-esteróides, pois é um análogo da prostaglandina E1, agindo como protetor da mucosa gástrica ${ }^{16,17}$. Contudo, com o conhecimento da população sobre sua ação abortiva, este medicamento passou a ser empregado de forma indiscriminada para interrupção da gravidez. Além de provocar o aborto por estimular diretamente o miométrio e induzir a contratibilidade uterina, ocasiona também hemorragias e pode levar ao óbito materno ${ }^{16-19}$.

Estudos realizados no Brasil mostram que grande número de casos de tentativa de aborto se deu pelo uso de medicamentos, principalmente o misoprostol, estrógeno ou progesterona ingerido por via oral ou por via injetável ${ }^{18}$.

A cada 1000 mulheres brasileiras estudadas, aproximadamente 22 utilizaram misoprostol sem êxito ${ }^{18}$. Tentativas frustradas com 0 uso deste medicamento pela própria gestante podem ter sérias complicações. A utilização do misoprostol tem sido relacionada ao desenvolvimento da síndrome de Moebius, uma doença congênita caracterizada pela paralisia dos nervos faciais e abducentes, estrabismo e malformações dos membros em crianças expostas a este medicamento durante a gestação ${ }^{19-22}$.

Pesquisas em um hospital do Rio de Janeiro indicam um percentual significativo (57\%) de mulheres internadas no hospital com complicações decorrentes à prática de aborto que relataram o uso do misoprostol para induzi-lo. Hemorragia vaginal e contrações uterinas foram os motivos mais comuns para procurar cuidados hospitalares. Apenas $8 \%$ das mulheres relataram efeitos colaterais gastrintestinais ${ }^{19}$.

Atualmente, no Brasil, a comercialização do misoprostol está proibida em farmácias de todo o país, por determinação da Portaria 344/98 do Ministério da Saúde, que regulamenta a distribuição de medicamentos sujeitos a controle especial. Sua utilização encontra-se restrita ao âmbito hospitalar sob supervisão da vigilância sanitária municipal ${ }^{20}$.

A eficácia da interrupção da gestação aumenta se o misoprostol for utilizado juntamente com o mifepristona ou se a associação for entre o misoprostol e o metotrexato, sendo este último disponível comercialmente com os nomes de: Metrotexato ${ }^{\circledR}$, Metrotex ${ }^{\circledR}$, Cytosafe ${ }^{\circledR}$, Metotrexim $^{\circledR 10,14,21}$. Estas associações são opções utilizadas para o tratamento clínico de abortos, conforme previsto no Art. 128 do Código Penal, em ambientes hospitalares ${ }^{7}$.

Os resultados do uso do mifepristona, tanto na via de administração sublingual quanto vaginal, mostram-se uma alternativa para a interrupção da gestação 22 . Esta substância se liga ao receptor de progesterona é um potente antagonista competitivo deste receptor. Os efeitos deste fármaco sobre o útero incluem necrose decidual, amadurecimento do colo uterino e aumento da contratilidade uterina ${ }^{21,23,24}$. A mifepristona não é comercializada no Brasil e no mercado internacional pode ser encontrada com as seguintes denominações: Mifegyne $^{\mathrm{TM}}$, Mifeprex ${ }^{\mathrm{TM}}$ e RU486 ${ }^{\mathrm{TM}}$.

Em muitos países europeus, incluindo Alemanha, Holanda, Áustria, Dinamarca, Finlândia, França, Noruega, Espanha, Suécia, Suíça e Reino Unido, a mifepristona é legalmente comercializada ${ }^{25}$

Em 1991, no Reino Unido, a mifepristona foi licenciada para a interrupção da gravidez de até 9 semanas de gestação e há relatados na literatura quanto à segurança, eficácia e boa aceitabilidade deste método. Já em 1995, a licença também passou a incluir gestações com mais de 13 semanas $^{26}$.

$\mathrm{Na}$ Itália, a mifepristona ainda não é comercializada devidoàs questões éticas, religiosas, morais e jurídicas. A Lei italiana 194/1978, que regula a maternidade e proteção da gravidez, considera o aborto cirúrgico, mas não menciona qualquer tipo de intervenção farmacológica ${ }^{25}$.

Em setembro de 2000, o Food and Drug Administration (FDA) aprovou a mifepristona para uso como abortivo nos Estados Unidos. O aborto é legalizado na maioria dos estados deste país e considerado um procedimento seguro, com mortalidade estimada em menos de 1 por 100000 $\operatorname{casos}^{27-29}$.

Já o metotrexato, outro fármaco utilizado como abortifaciente, atua bloqueando a enzima diidrofolato redutase, envolvida na produção de tiamina durante a síntese de DNA, e age sobre o citotrofoblasto interrompendo o processo de implantação ${ }^{21}$. É um antifolato amplamente utilizado para o tratamento da leucemia linfoblástica aguda, sendo também aplicado no tratamento de artrite reumatóide e de outras doenças inflamatórias, pois age como anti-inflamatório e imunomodulador ${ }^{27}$. 
Entre 1991-1995, um estudo sobre as substâncias frequentemente utilizadas para interrupção da gravidez, realizado em 874 gestantes brasileiras, mostrou que, além do misoprostol, utilizado em $15,2 \%$ das ocorrências, a ingestão de progesterona associada ao estradiol e ao acetato de medroxiprogesterona representou $29,3 \%$ dos casos. Para induzir o fluxo menstrual, 1,4\% administraram analgésicos e antiinflamatórios, como o ácido acetilsalicílico e houve $5,7 \%$ de relatos de associações de substâncias que não puderam ser identificadas ${ }^{28}$.

\section{Plantas utilizadas como abortivas}

Vegetais e extratos de plantas são utilizados desde o início da civilização pela humanidade com inúmeras finalidades, inclusive abortivas. Observase que a utilização destas preparações continua em uso por diversas culturas em todo o mundo ${ }^{29}$.

A ingestão de plantas para induzir o aborto envolve o risco de intoxicação grave, que pode resultar em morte ou futuras complicações reprodutivas. Não se encontram muitas publicações sobre este assunto e pesquisas sobre cada espécie de plantas ajudariam a aumentar a conscientização e a compreensão dos efeitos tóxicos do uso de plantas com finalidade abortiva ${ }^{30}$.

Entretanto, há alguns estudos que propõem mecanismos de ação de plantas que ocasionam aborto, conforme Tabela 1. As falhas na implantação do embrião são uma das principais causas de aborto e podem estar ligadas à exposição materna, interferindo com este evento por diferentes mecanismos que incluem: alterações morfológicas do embrião e fetotoxicidade ${ }^{31-34}$, alterações dos níveis hormonais ${ }^{35-38}$ e alterações uterinas ${ }^{39-42}$.

Tabela 1. Plantas estudadas como abortivas, mostrando seus nomes científicos e populares quando disponíveis (entre parênteses), mecanismo(s) de ação(ões) proposto(s) e referências bibliográficas ("Refs")

\begin{tabular}{|c|c|c|}
\hline $\begin{array}{c}\text { PLANTA } \\
\text { Nome científico (nome popular) }\end{array}$ & Mecanismo de ação proposto & Refs \\
\hline $\begin{array}{l}\text { Garcinia mangostana (Mangostão) e Psidium } \\
\text { guajava (Goiabeira) }\end{array}$ & Alterações morfológicas do embrião e fetotoxicidade. & 31 \\
\hline $\begin{array}{l}\text { Acanthospermum hispidum (Delegado) e } \\
\text { Cajanus cajan (Feijão cuandu) }\end{array}$ & $\begin{array}{l}\text { Estudos em animais evidenciaram ação abortiva e } \\
\text { teratogênica. }\end{array}$ & 32 \\
\hline Punica granatum (Romã) & Embriotoxicidade. & 33 \\
\hline Ruta graveolens (Arruda) & $\begin{array}{l}\text { Perdas na pré-implantação, falhas na implantação ou } \\
\text { alterações em processos fisiológicos materno da gestação } \\
\text { subjacente. }\end{array}$ & 34 \\
\hline Inula viscosa (nome popular não informado) & Ação anti-implantação e efeito luteolítico. & 35 \\
\hline Maytenus ilicifolia (Espinheira-Santa) & $\begin{array}{l}\text { Perda de pré-implantação embrionária, mas sem efeito } \\
\text { sobre organogênese. Atividade estrogênica do extrato, } \\
\text { exibida pelo efeito uterotrófico, sugere interferência na } \\
\text { receptividade do útero para o embrião. }\end{array}$ & 36 \\
\hline $\begin{array}{l}\text { Rivea hypocrateriformis (nome popular não } \\
\text { informado) }\end{array}$ & $\begin{array}{l}\text { Propriedade anti-implantação e de interrupção da gravidez } \\
\text { precoce. Atividade anti-fertilidade foi reversível com a } \\
\text { administração de progesterona. No entanto, o extrato é } \\
\text { ineficaz na interrupção da gravidez tardia. }\end{array}$ & 37 \\
\hline Acalypha indica (Khokali ou miado de gato) & $\begin{array}{l}\text { Ação anti-implantação. A atividade anti-fertilidade é } \\
\text { reversível pela suspensão do tratamento com o extrato (que } \\
\text { apresenta ação estrogênica e atua como anti-nidante). }\end{array}$ & 38 \\
\hline Salvia fruticosa (Salvia) & $\begin{array}{l}\text { Atividade anti-implantação, anti-fertilidade e toxicidade } \\
\text { reprodutiva. Redução do número de fetos viáveis e } \\
\text { aumento do número de reabsorção fetal. }\end{array}$ & 39 \\
\hline Peganum harmala (Arruda Síria) & Aumenta reabsorção fetal e diminui a implantação. & 40 \\
\hline Sida veronicaefolia (Cajazeira) & Ocitotóxico (que produz hipertonia uterina) & 41 \\
\hline Coleus barbatus (Boldo) & $\begin{array}{l}\text { Efeito anti-implantação ou caso a ingestão ocorra } \\
\text { após a implantação do embrião, observa-se atraso no } \\
\text { desenvolvimento do feto. }\end{array}$ & 42 \\
\hline
\end{tabular}


Em relação às malformações, o período de pré-implantação em mamíferos é a etapa na qual pode ocorrer letalidade ao embrião ou interferência no desenvolvimento normal do mesmo ${ }^{31}$. No entanto, alguns autores relataram um aumento no número de variações em fetos cujas mães foram expostas aos agentes químicos do vegetal durante este período, bem como atraso no desenvolvimento fetal e morte antes do nascimento ${ }^{32,33}$. Estudos de embriotoxicidade mostram que a administração do extrato da casca da romã (Punica granatum) induz apoptose e fragmentação no DNA em linhagens celulares de humanos ${ }^{33}$

A administração do extrato de Sida veronicaefolia, conhecida popularmente como cajazeira, pode causar a morte fetal pela capacidade de causar contração uterina contínua e aumento de pressão intraplacentária ${ }^{41}$.

Tem sido verificado que a Ruta graveolens, popularmente conhecida como arruda, causa alterações no período organogênico, alterando a histologia da placenta e do feto; influenciando na atividade angiogênica ${ }^{34}$

Rao e Hoffman ${ }^{43}$ relatam um caso de uma mulher que apresentou taquicardia, sudorese, dor abdominal, vômitos e fraqueza muscular após o uso de Caulophyllum thalictroides (cohosh azul) em uma tentativa de induzir aborto; estes sintomas indicam toxicidade nicotínica.

Outro estudo cita o caso de ingestão de cânfora, que é extraída do Cinnamomum camphora para induzir o aborto. A cânfora está presente em preparações medicamentosas, principalmente para uso externo, e é facilmente disponível em farmácias. A substância é altamente tóxica quando administrada por via oral e pode levar ao aborto, pois atravessa a placenta e o feto não apresenta capacidade de metabolização enzimática para eliminar este agente tóxico ${ }^{44}$.

A medicina tradicional brasileira na área das plantas medicinais é uma das mais importantes do mundo devido à vasta biodiversidade e ao conjunto de lendas, crenças, costumes e tradições provenientes da fusão das culturas indígena, africana e européia ${ }^{45}$. Ainda de acordo com estudo, o "Inventário de Plantas Medicinais do Estado da Bahia" mostra que, entre as plantas indicadas pelas mulheres utilizadas como abortivas, apenas a quina verdadeira (Cinchona calysaya), hortelã (Mentha pulegium) e romã (Punica granatum) apresentam esta propriedade, justificando a ineficácia da maioria dos outros chás relacionados. Em relação à arruda (Ruta graveolens), observam que o seu uso mais frequente e popular é como emenagoga, provocando a menstruação e aumentando o fluxo; entretanto, em doses maiores atua como abortivo. De fato, neste estudo foi verificado que, das plantas utilizadas pelas mulheres durante a gravidez, nem todas tinham propriedades abortivas comprovadas cientificamente ${ }^{21}$.

A Secretaria de Estado de Saúde do Município do Rio de Janeiro publicou uma Resolução ${ }^{46}$ que contra-indica o uso de plantas medicinais, com a finalidade de orientar e legislar sobre o uso destas, durante $01^{\circ}$ trimestre de gestação e lactação e cujos estudos toxicológicos não estão ainda concluídos. Tal resolução lista inúmeros vegetais conhecidos popularmente como agentes indutores de aborto.

\section{CONCLUSÃO}

Nos últimos anos, muito se discute sobre a possível legalização do aborto no Brasil nos casos não contemplados na atual legislação, como forma de minimizar as consequências das tentativas inapropriadas de interrupção da gravidez. É inegável que a ilegalidade desse ato é um fator que faz com que mulheres nessa situação busquem formas clandestinas para realizá-lo, valendo-se de indicações populares sem respaldo científico, expondo-se a riscos para sua saúde e podendo provocar sequelas na criança, quando a tentativa de aborto é mal sucedida. Isso é observado tanto com a administração de fármacos como com o uso de preparados de plantas.

Todas as complicações que um aborto pode acarretar à saúde materna e fetal motivam o desenvolvimento de pesquisas envolvendo os mecanismos de ação, os efeitos, as reações adversas, toxicidade de plantas e medicamentos utilizados nas práticas de aborto. Esses estudos são importantes para a criação de formas eficazes de tratamento de complicações decorrentes do uso inadequado de substâncias abortivas em gestantes.

Em países onde o aborto é legalizado e assistido por médicos, o risco de problemas de saúde é consideravelmente diminuído. Entretanto, a discussão da legalização do aborto no Brasil não é só considerada sob o ponto de vista técnico. Grande parte da população brasileira é extremamente religiosa, o que acaba influenciando as decisões políticas do país. Desta forma, não deverá ocorrer, a curto e médio prazo, uma alteração substancial do atual panorama da legislação no que concerne a esse assunto.

Atualmente, o Ministério da Saúde disponibiliza, através do programa "Política Nacional de Atenção Integral à Saúde da Mulher"47, vários medicamentos e métodos contraceptivos, como, 
Roehsig M, et al. Abortifacientes: efeitos tóxicos e riscos.

por exemplo: anticoncepcional injetável trimestral e mensal, pílula oral combinada, diafragma, dispositivo intra-uterino (DIU), preservativo masculino e feminino, pílula de emergência ("pílula do dia seguinte"), minipílula. Neste mesmo documento do Ministério da Saúde, verifica-se baixa adesão das mulheres no uso contínuo de anticoncepcionais orais, uma vez que $43 \%$ delas interrompem o uso nos 12 primeiros meses após o início ${ }^{47}$.

Devido à legislação do aborto ser restritiva no Brasil, programas de conscientização e orientação do uso de medicamentos e métodos contraceptivos são de fundamental importância para se evitar uma gravidez não planejada e, posteriormente, a tentativa de aborto clandestino, o qual pode colocar em risco a saúde da mulher e da criança gerada.

Roehsig M, Sant'Anna SG, Salles KRRD, Santos MF, Yonamine M. Abortive agents: toxic effects and risks. Saúde, Ética \& Justiça. 2011;16(1):1-8.

ABSTRACT: The illegal practice of abortion can cause many adverse effects to women's health. In many cases, the political, social and religious situation in Brazil can lead to the self-administration of drugs and popular preparations to induce abortion. Currently, drugs and homemade medicines are some of the methods used to interrupt pregnancy. There are different laws to regulate abortion procedures among countries, with a tendency of acceptance of pregnancy interruption in developed countries. The participation of the public services regarding people's education and family planning is essential, so that each person would be able to evaluate their choices and the risks involved. The objective of this paper was to review toxicological aspects of drugs and plants used as abortive agents, taking into consideration the risks involved in cases in which medical assistance is not adequately addressed.

KEY WORDS: Abortifacient agents/toxicity; Abortifacient agents/adverse effects; Women's health; Toxicity.

\section{REFERÊNCIAS}

1. Grimes DA. The safety of oral contraceptives: epidemiologic insights from the first 30 years. Am J Obstet Gynecol. 1992;188:1950-4.

2. JHU - Population Information Program. O planejamento da atenção médica para salvar a vida da mulher. Population Rep. 1997;10:7-11.

3. Serviço Nacional de Informações TóxicoFarmacológicas (SINITOX) [citado em 11 abr. 2011] Disponível em: http://www.fiocruz.br/sinitox_novo/ cgi/cgilua.exe/sys/start.htm?sid $=319$.

4. Monteiro MFG, Adesse L. Estimativas de aborto induzido no Brasil e grandes regiões 1992-2005. In: XV Encontro Nacional de Estudos Populacionais, ABEP, Caxambu, MG; 2006.

5. WHO. Safe abortion: technical and policy guidance for health systems. Geneva; 2003.

6. WHO. Baltar da Rocha MI. The abortion issue in Brazil: a study of the debate in congress. Estudos Feministas. 1996;4:505-22.

7. Brasil. Código penal. 39a ed. São Paulo: Saraiva; 2001.

8. Câmara dos Deputados [citado em 15 dez. 2008]. Disponível em: -http://www.camara.gov.br/Sileg/ Prop_Detalhe.asp? id=16299.

9. Brasil. Ministério da Saúde. Política Nacional de Atenção Integral à Saúde da Mulher - Plano de Ação 2004 - 2007. Departamento de Ações Programáticas Estratégicas do Ministério da Saúde, Série C.
Projetos, programas e relatórios. Brasília, DF; 2004.

10. Fialaa C, Gemzell-Danielssonb K. Review of medical abortion using mifepristone in combination with a prostaglandin analogue. Contraception. 2006;74:6686.

11. WHO. Bulletin de L'Organisation Mondiale de la Santé - Recueil d'articles № 3 - Eliminer les risques liés à l'avortement: lê devoir d'une bonne politique de santé publique / Making Abortions Safe: A Matter of Good. Public health policy and practice. Genève; 2000.

12. Singh S. Hospital admissions resulting from unsafe abortion: estimates from 13 developing countries. Lancet. 2006;368:1887-92.

13. Berer M. Bull World Health Org. 2000;78.

14. Cheng L. Medical abortion in early pregnancy: experience in China. Contraception. 2006;74:61-5.

15. Alan Guttmacher Institute. Clandestine abortion: a latin american reality. New York; 1994.

16. Rang HP, Dale MM, Ritter JM. Farmacologia. 3a ed. Rio de Janeiro: Guanabara Koogan; 1997.

17. Brunton LL, Lazo JS, Parker KL. Goodman \& Gilman: as bases farmacológicas da terapêutica. 11a ed. Rio de Janeiro: McGraw; 2007.

18. Mengue SS, Schenke IEP, Duncan BB, Scmhmidt I. Prevalence and clinical correlates of unsuccessful use of drugs to induce menstruation. Contraception. 
Roehsig M, et al. Abortifacientes: efeitos tóxicos e riscos.

1998;57(2):93-7.

19. Costa SH, Vessey MP. Misoprostol and illegal abortion in Rio de Janeiro, Brazil. Lancet. 1993;341:1258-61.

20. Portaria SVS/MS 344 de 12 de maio de 1998 Aprova o Regulamento Técnico sobre substâncias e medicamentos sujeitos a controle especial.

21. Hardman JG, Gilman AG, Limbird LE. Goodman \& Gilman's the pharmacological basis of therapeutics. 9th ed. New York: McGraw-Hill; 1996.

22. LippA.Areview of developments in medicaltermination of pregnancy. J Clin Nursing. 2008;17:1411-8.

23. Zhu Q, Gao E, Chen A, Luo L, Cheng Y, Yuan W. Mifepristone-induced abortion and placental complications in subsequent pregnancy. Human Reproduct. 2009;24:315-9.

24. Sitruk-Ware, R. Mifepristone and misoprostol sequential regimen side effects, complications and safety. Contraception. 2006;74:48-55.

25. Banfi R, Pavone E, Cerri R, Menichetti M. Mifepristone in Italy: the case of a drug trapped between ethics and clinical practice. Pharm World Sci. 2007;29:400-3.

26. Hamoda H, Ashok PW, Flett GMM, Templeton A. Medical abortion at 9-13 weeks gestation: a review of 1076 consecutive cases. Contraception. 2005;71:327-32.

27. Svirsky R, RozovskiU, Vaknin Z, Pansky M, Schneider D, Halperin R. The safety of conception occurring shortly after methotrexate treatment of an ectopic pregnancy. Reproduct Toxicol. 2009;27:85-7.

28. Mengue SS, Schenkela EP, Duncanb BB, Schmidtb MI. Drugs most frequently used to "start the menstrual flow" classified by class and the products used most frequently. Brazilian Study of Gestational. Diabetes. 1991;57:93-7.

29. Mahmoudian M, Jalilpour $H$, Salehian P. Toxicity of Peganum harmala: Review and a case report. Iranian J Pharmacol Therap. 2002;1:1-4.

30. Ciganda, Labord A. Herbal infusions used for induced abortion. J Toxicol. 2003;41(3):235-9.

31. Settheetham W, Ishida T. Study of genotoxic effects of antidiarrheal medicinal herbs on human cells in vitro. Southeast Asian J Trop Med Public Health. 1995;26:306-10.

32. Lemonica IP, Alvarenga CMD. Abortive and teratogenic effect of Acanthospermum hispidum DC. and Cajanus cajan (L.) Millps. in pregnant rats. J Ethnopharmacol. 1994;43:39-44.

33. Vidal A, Fallarero A, Peña BR, Medina ME, Gra B, Rivera F, Gutierrez Y, Vuorela PM. Studies on the toxicity of Punica granatum $L$. $(P)$ whole fruit extracts. J Ethnopharmacol. 2003;89:295-300.
34. Freitas TG, Augusto PM, Montanari T. Effect of Ruta graveolens $L$ on pregnant mice. Contraception, 2005;71:74-7.

35. Al-Dissi NM, Salva AS, Al-Haji HA. Effects of Inula viscosa leaf extracts on abortion and implantation in rats. J Ethnopharmacol. 2001;77:117-21.

36. Montanari T, Bevilaqua E. Effect of Maytenus ilicifolia Mart on pregnant mice. Contraception. 2002;65:171-5.

37. Shivalingappa H, Satyanaryan ND, Purohit MG. Antiimplantation and pregnancy interrruption efficacy of Rivea hypocrateriformis in the rat. $J$ Ethnopharmacol. 2001;74:245-9.

38. Shivalingappa H, Satyanaryan ND, Purohit MG. Antiimplantation and pregnancy interrruption efficacy of Rivea hypocrateriformis in the rat. J Ethnopharmacol. 2001;74:245-9.

39. Elbetieha A, Al-Hamooda MH, Alkofahic A, Batainehd H. Reproductive toxicity potentials of Salvia fruticosa (L) in rats. J Ethnopharmacol. 1998;61: 67-74.

40. Shapira Z, Terkel J, Egozi Y, Nyska A, Fiedman J. Abortifacient potential for the epigeal parts of Peganum harmala. J Ethnopharmacol. 1989;27:31925 .

41. Lutterodt GD. Abortifacient properties of an extract from Sida veronicaefolia. J Ethnopharmacol. 1988;23:27-37.

42. Almeida FCG, Lemonica IP. The toxic effects of Coleus barbarus B. on the different periods of pregnancy in rats. J Ethnopharmacol. 2000;73:5360.

43. Rao RB, Hoffman RS. Nicotinic toxicity from tincture of blue cohosh (Caulophyllum thalictroides) used as an abortifacient. Veter Human Toxicol. 2002;44:221-3.

44. Rabl W, Katzgraber F, Steinlechner M. Camphor ingestion for abortion (case report). Forensic Sci Int. 1997;89:137-40.

45. Costa Neto EM, Santos LM, Santos SAS, Magalhães SF, Amorim TC. Utilização de plantas medicinais relacionadas a eventos do ciclo reprodutivo feminino no distrito de Oliveira dos Campinhos, Santo Amaro, Bahia. Sitientibus Série Ciências Biol. 2005;5:125-7.

46. Brasil. Secretaria de Saúde do Estado do Rio de Janeiro. Resolução oㅜ 1757, de 18 de fevereiro de 2002. Diário Oficial Est Rio de Janeiro; 20 fev. 2002.

47. Brasil. Ministério da Saúde. Secretaria de Atenção à Saúde. Departamento de Ações Programáticas Estratégicas. Política Nacional de Atenção Integral à Saúde da Mulher. 2004. Disponível em: http:// bvsms.saude.gov.br/bvs/publicacoes/politica_nac_ atencao_mulher.pdf 